\title{
A modified H-bridge multilevel inverter for photovoltaic system
}

\author{
Nasrudin Abd Rahim, Krismadinata Chaniago, and Jeyraj Selvaraj ${ }^{\text {a) }}$ \\ Department of Electrical Engineering, University of Malaya 50603 Kuala Lumpur, \\ Malaysia \\ a) jeyraj95@um.edu.my
}

\begin{abstract}
This paper presents a modified H-bridge seven-level singlephase grid-connected inverter for photovoltaic system with a novel pulse-width-modulated (PWM) control scheme. The inverter is capable of producing seven output-voltage levels $\left(\mathrm{V}_{\mathrm{dc}}, 2 \mathrm{~V}_{\mathrm{dc}} / 3, \mathrm{~V}_{\mathrm{dc}} / 3,0\right.$, $\left.-\mathrm{V}_{\mathrm{dc}},-2 \mathrm{~V}_{\mathrm{dc}} / 3,-\mathrm{V}_{\mathrm{dc}} / 3\right)$ from the dc supply voltage. Perturb and Observe $(\mathrm{P} \& \mathrm{O})$ algorithm is used to extract maximum power from the $\mathrm{PV}$ module. MPPT and current control algorithm were implemented in an eZdsp board, TMS320F2812. The proposed system was implemented in a prototype.
\end{abstract}

Keywords: multilevel inverter, PWM, current control

Classification: Science and engineering for electronics

\section{References}

[1] P. K. Hinga, T. Ohnishi, and T. Suzuki, "A New PWM Inverter for Photovoltaic Power Generation System," Conf. Rec. IEEE PESC 1994, pp. 391395.

[2] M. Calais and V. G. Agelidis, "Multilevel converters for single-phase grid connected photovoltaic systems - an overview," Proc. IEEE ISIE, vol. 1, pp. 224-229, 1998.

[3] V. G. Agelidis, D. M. Baker, W. B. Lawrance, and C. V. Nayar, "A Multilevel PWM Inverter Topology for Photovoltaic Application," IEEE ISIE'1997, Guimäes, Portugal, pp. 589-594.

[4] J. Selvaraj and N. A. Rahim, "Multillevel inverter for grid connected PV system employing digital PI controller," IEEE Trans. Ind. Electron., vol. 56, no. 1, pp. 497-505, Jan. 2009

[5] S. J. Park, F. S. Kang, M. H. Lee, and C. U. Kim, "A New Single-Phase Five-Level PWM Inverter Employing a Deadbeat Control Scheme," IEEE Trans. Power Electron., vol. 18, no. 3, pp. 831-843, May 2003.

[6] A. Pandey, B. Singh, B. N. Singh, A. Chandra, K. Al-Haddad, and D. P. Kothari, "A Review of Multilevel Power Converters," IE(I) Journal EL, vol. 86, pp. 220-231, March 2006.

[7] N. A. Rahim, J. Selvaraj, and K. Chaniago, "A Novel PWM Multilevel Inverter for PV Application," IEICE Electron. Express, vol.6, no.15, pp.1105-1111, Aug. 2009. 


\section{Introduction}

Various single-phase grid-connected inverter topologies for low-power photovoltaic systems have been suggested or used. Recently, multilevel inverter topologies are popular in photovoltaic systems. Multilevel inverters offer several advantages over H-bridge conventional inverter. They have nearlysinusoidal output-voltage waveforms, output current with better harmonic profile, less stressing of electronic components owing to decreased voltages, switching losses that are lower than those of conventional two-level inverters, a smaller filter size, and lower EMI; all making them cheaper, lighter, and more compact $[1,2,3,4]$.

Various topologies for multilevel inverter have been proposed. Common ones are diode-clamped, flying capacitor or multicell, cascaded H-bridge, and modified H-bridge multilevel [6]. The modified H-bridge topology is significantly advantageous over other topologies; less power switch, less anti-parallel diodes, power diodes, and less capacitors for inverters of the same number of levels.

This paper recounts the development of a novel modified H-bridge singlephase multilevel inverter that has two diode-embedded bidirectional switches and a novel PWM technique. The topology was applied to a grid-connected photovoltaic system with considerations for a maximum-power-point tracker and a current-control algorithm.

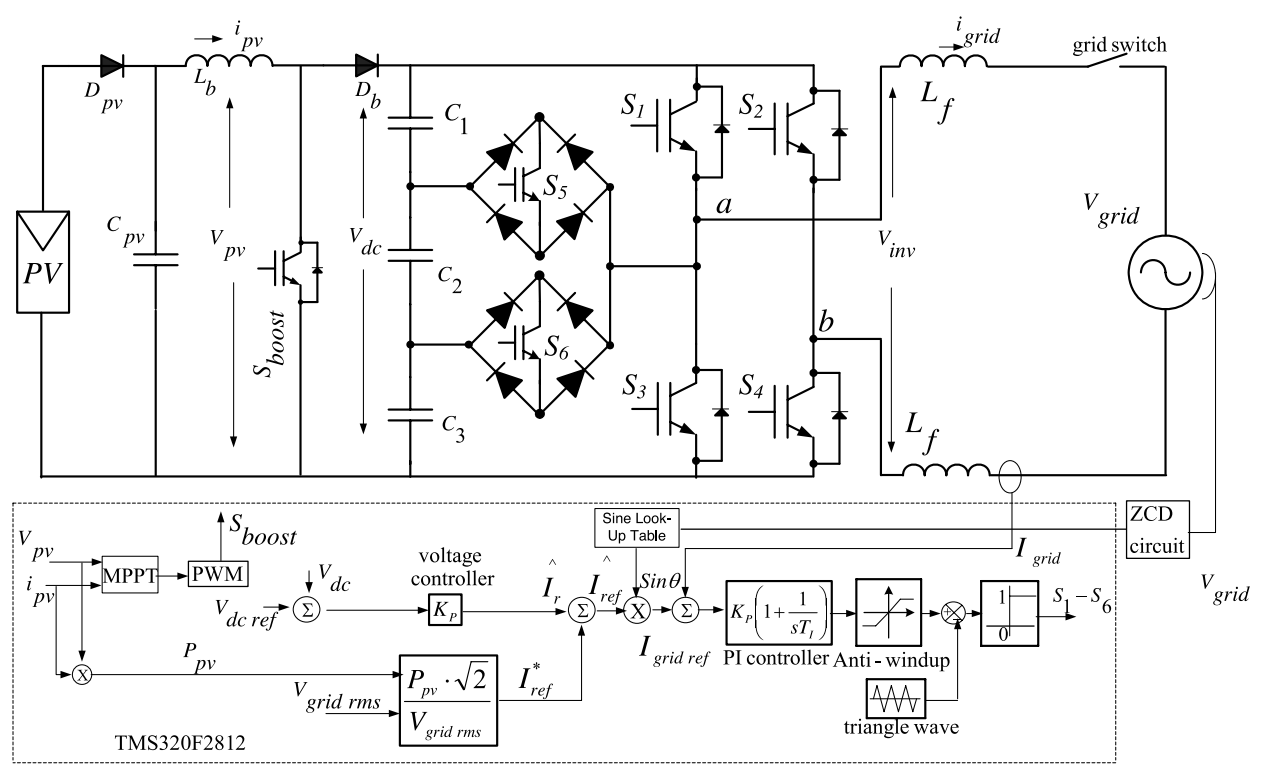

Fig. 1. The proposed multilevel inverter with control algorithm

\section{Proposed multilevel inverter topology}

The proposed topology comprises a single-phase conventional H-bridge inverter, two bidirectional switches, and a capacitor voltage divider formed by $\mathrm{C}_{1}, \mathrm{C}_{2}$, and $\mathrm{C}_{3}$ as in Fig. 1. Although voltage balancing at each capacitor is 
not perfectly balanced, it is still achievable by placing a large capacitor for $\mathrm{C}_{1}, \mathrm{C}_{2}$, and $\mathrm{C}_{3} \mathrm{PV}$ arrays with blocking diode $D_{p v}$ and capacitor $C_{p v}$ were connected to the inverter via a DC-DC boost converter. As this topology is used in a grid-connected system, the power from the PV solar arrays is transferred to the power network rather than to a load. The DC-DC boost converter is used to step up inverter output voltage $V_{\text {inv }}$ to more than $\sqrt{ } 2$ of grid voltage $V_{g}$ to ensure power flow from PV arrays to the grid. Since no transformer is used, $\mathrm{V}_{\text {inv }}$ should be more than $340 \mathrm{~V}$ (assuming $\mathrm{V}_{\mathrm{g}}=240 \mathrm{~V}$ ). A filtering inductance $L_{f}$ was used to filter the current injected into the grid.

Proper switching of the inverter can produce seven output-voltage levels. Table I shows the switching combinations that generated the seven outputvoltage levels ( $\mathrm{Vdc}, 2 \mathrm{Vdc} / 3, \mathrm{Vdc} / 3,0,-\mathrm{Vdc},-2 \mathrm{Vdc} / 3,-\mathrm{Vdc} / 3$ ). For voltage level $0^{*}$ or 0 , they are the same, however, for commutation purposes, the switch configuration is different for the zero voltage level in the first half cycle of the output voltage from that in the second half cycle.

Table I. output voltage according to switches on-off condition

\begin{tabular}{|c|c|c|c|c|c|c|}
\hline Vinv & S1 & S2 & S3 & S4 & S5 & S6 \\
\hline $\mathrm{Vdc}$ & on & off & off & on & off & off \\
\hline $2 \mathrm{Vdc} / 3$ & off & off & off & on & on & off \\
\hline $\mathrm{Vdc} / 3$ & off & off & off & on & off & on \\
\hline 0 & off & off & on & on & off & off \\
\hline $0^{*}$ & on & on & off & off & off & off \\
\hline$-\mathrm{Vdc} / 3$ & off & on & off & off & on & off \\
\hline$-2 \mathrm{Vdc} / 3$ & off & on & off & off & off & on \\
\hline$-\mathrm{Vdc}$ & off & on & on & off & off & off \\
\hline
\end{tabular}

\section{PWM modulation}

A novel PWM modulation technique was introduced to generate the PWM switching signals. Three reference signals, $V_{\text {ref } 1}, V_{\text {ref } 2}$ and $V_{\text {ref } 3}$ were in turns compared with the carrier signal $V_{\text {carrier }}$. The reference signals had the same frequency and amplitude, and were in phase with an offset value equivalent to the amplitude of the carrier signal. The reference signals were each compared with the carrier signal. If $V_{\text {ref } 1}$ had exceeded the peak amplitude of $V_{\text {carrier }}$, $V_{\text {ref2 }}$ was compared with $V_{\text {carrier }}$ until it had exceeded the peak amplitude of $V_{\text {carrier }}$. Then onwards, $V_{\text {ref } 3}$ would take charge and would be compared with $V_{\text {carrier }}$ until it reached zero. Once $V_{\text {ref3 }}$ had reached zero, $V_{\text {ref2 }}$ would be compared until it reached zero. Then onwards, $V_{r e f 1}$ would be compared with $V_{\text {carrier }}$. Fig. 2 shows the resulting switching pattern. Switches $\mathrm{S}_{1}, \mathrm{~S}_{3}, \mathrm{~S}_{5}$, and $\mathrm{S}_{6}$ would be switching at the rate of the carrier signal frequency, whereas $\mathrm{S}_{2}$ and $\mathrm{S}_{4}$ would operate at a frequency equivalent to the fundamental frequency.

For one cycle of the fundamental frequency, the proposed inverter operated through six modes. The six modes are described as follows:

Mode 1: $0<\omega t<\theta_{1}$, and $\theta_{4}<\omega t<\pi$

Mode 2: $\theta_{1}<\omega t<\theta_{2}$, and $\theta_{3}<\omega t<\theta_{4}$ 
Mode 3: $\theta_{2}<\omega t<\theta_{3}$

Mode 4: $\pi<\omega t<\theta_{5}$, and $\theta_{8}<\omega t<2 \pi$

Mode 5: $\theta_{5}<\omega t<\theta_{6}$, and $\theta_{7}<\omega t<\theta_{8}$,

Mode 6: $\theta_{6}<\omega t<\theta_{7}$,

The phase angle $\theta_{1}-\theta_{7}$ depends on modulation index $M_{a}$. Theoretically, for a single reference signal and a single carrier signal, the modulation index is defined to be

$$
M_{a}=\frac{A_{m}}{A_{c}}
$$

While for dual reference signal and single carrier signal, the modulation index is defined to be [7]

$$
M_{a}=\frac{A_{m}}{2 A_{c}}
$$

As the proposed seven-level PWM inverter uses three reference signals, the modulation index is defined to be

$$
M_{a}=\frac{A_{m}}{3 A_{c}}
$$

Where $A_{c}$ is the per unit (pu) peak-to-peak value of the carrier signal, and $A_{m}$ is the (pu) peak value of the voltage reference signal $V_{r e f}$.

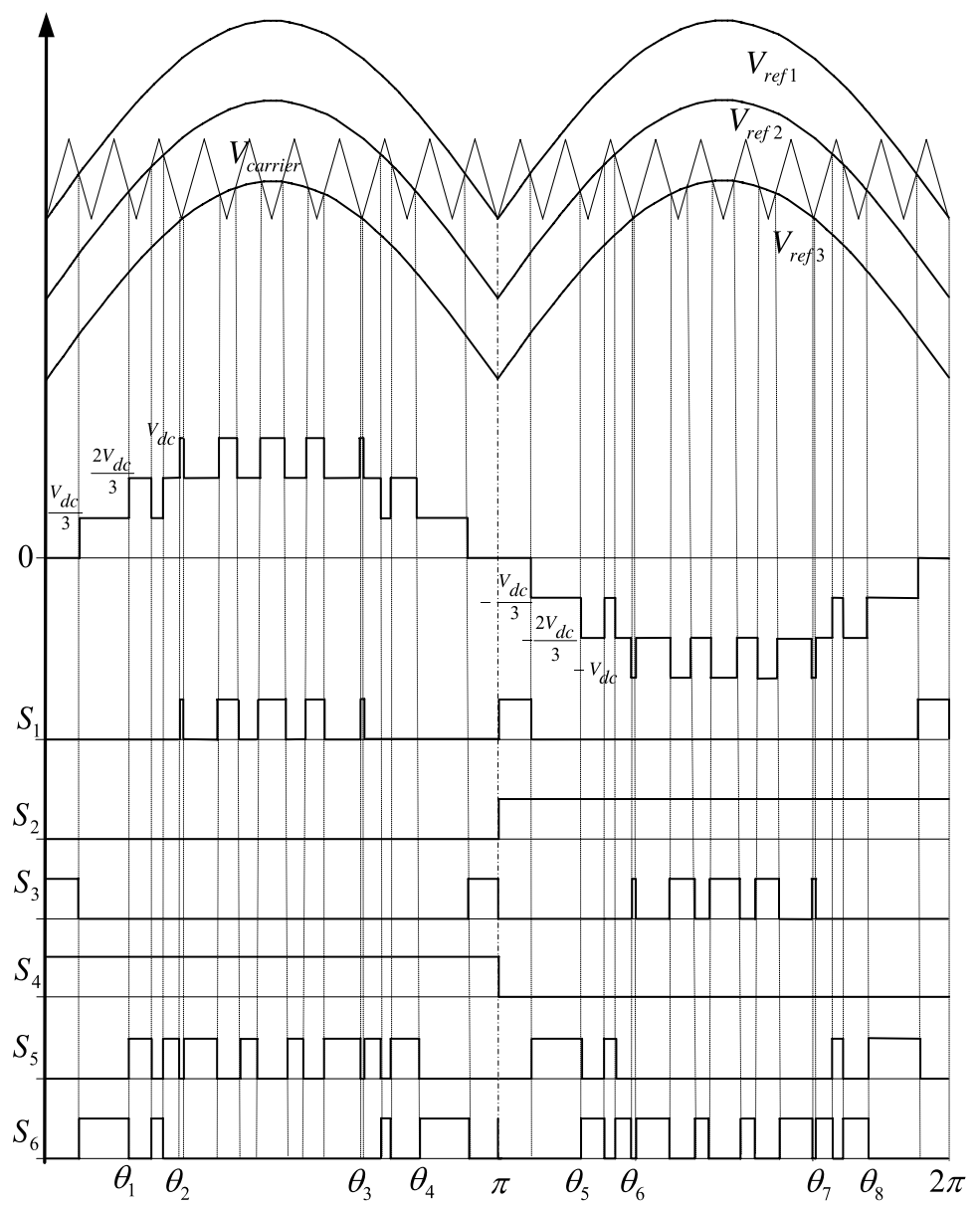

Fig. 2. Switching pattern for the single-phase seven-level inverter 
When the modulation index is less than 0.33 , the phase-angle displacement is

$$
\begin{aligned}
& \theta_{1}=\theta_{2}=\theta_{3}=\theta_{4}=\frac{\pi}{2} \\
& \theta_{5}=\theta_{6}=\theta_{7}=\theta_{8}=\frac{3 \pi}{2}
\end{aligned}
$$

On the other hand, when the modulation index is more than 0.33 and less than 0.66 , the phase-angle displacement is determined by

$$
\begin{aligned}
& \theta_{1}=\sin ^{-1}\left(\frac{A_{c}}{A_{m}}\right) \quad ; \quad \theta_{2}=\theta_{3}=\frac{\pi}{2} ; \quad \theta_{4}=\pi-\theta_{1} ; \\
& \theta_{5}=\pi+\theta_{1} ; \quad \theta_{6}=\theta_{7}=\frac{3 \pi}{2} ; \quad \theta_{8}=2 \pi-\theta_{1}
\end{aligned}
$$

If the modulation index is more than 0.66 , the phase-angle displacement is determined by

$$
\begin{aligned}
\theta_{1} & =\sin ^{-1}\left(\frac{A_{c}}{A_{m}}\right) ; & \theta_{2} & =\sin ^{-1}\left(\frac{2 A_{c}}{A_{m}}\right) \\
\theta_{3} & =\pi-\theta_{2} ; & \theta_{4} & =\pi-\theta_{1} ; \\
\theta_{5} & =\pi+\theta_{1} ; & \theta_{6} & =\pi+\theta_{2} ; \\
\theta_{7} & =2 \pi-\theta_{2} ; & \theta_{8} & =2 \pi-\theta_{1} .
\end{aligned}
$$

For $M_{a}$ equal to, or less than, 0.33 , only the lower reference wave, $V_{\text {ref } 3}$ is compared with the triangular carrier signal. The inverter's behavior is similar to a conventional full-bridge three-level PWM inverter. However, if $M_{a}$ is more than 0.33 and less than 0.66 , only $V_{\text {ref } 2}$ and $V_{\text {ref } 3}$ reference signals are compared with the triangular carrier wave. The output voltage consists of five dc-voltage levels. The modulation index is set to be more than 0.66 , for seven levels of output voltage to be produced. Three reference signals have to be compared with the triangular carrier signal to produce switching signals for the switches.

\section{Control system}

Fig. 1 shows the control system, which comprises a maximum-power-point tracker (MPPT) algorithm, a DC-bus voltage controller, reference-current generation, and a current controller. Two main tasks of the control system are maximization of the energy transferred from the PV arrays to the grid, and generation of a sinusoidal current with minimum harmonic distortion, also with grid-voltage harmonics present. The proposed inverter uses the $\mathrm{P} \& \mathrm{O}$ algorithm for its wide usage in MPPT owing to its simple structure and requirement of only a few measured parameters. It periodically perturbs (i.e., increment or decrement) the array terminal voltage and compares the PV output power with that of the previous perturbation cycle. If the power increased the perturbation continues in the same direction in the next cycle, otherwise, the direction reverses. This means the array terminal voltage is perturbed every MPPT cycle; therefore, when the MPP is reached, the P\&O algorithm oscillates around it.

$\mathrm{P} \& \mathrm{O}$ algorithm was implemented in the DC-DC boost converter. The output of the MPPT is the duty-cycle function. As the dc-link voltage $\mathrm{V}_{\mathrm{DC}}$ 
was controlled in the DC-AC seven-level PWM inverter, the change of the duty-cycle changes voltage at the output of the PV panels. A DC voltage controller with proportional gain was implemented to keep the output voltage of the dc-dc boost converter, $V_{d c}$, constant, by comparing $V_{d c}$ and $V_{d c r e f}$ and feeding the error into the voltage controller which then tries to reduce the error. In this way, $V_{d c}$ can be maintained, and at more than $\sqrt{ } 2$ of $V_{\text {grid }}$ to inject power into the grid.

To deliver energy to grid, frequency and phase of the PV inverter must equal those of the grid; therefore a grid synchronization method is needed. The sine lookup table that generates reference current must be brought into phase with the grid voltage $\left(V_{\text {grid }}\right)$. For this, the grid period and phase must be detected. The proposed inverter provides an analog zero-crossing detection (ZCD) circuit on one of its input ports where the grid voltage is to be connected. The zero-crossing circuit then produces an in-phase square-wave output which is fed into the digital I/O port on the eZdsp board, TMS320F2812.

PI algorithm was used as the feedback current controller for the application. The current injected into the grid, also known as grid current $I_{\text {grid }}$, was sensed and fed back to a comparator that compared it with the reference current $I_{\text {gridref }}$. $I_{\text {gridref }}$ is the result of the MPPT algorithm. The error from comparing $\mathrm{I}_{\text {grid }}$ with $I_{\text {gridref }}$ was fed into the PI controller. The output of the PI controller, known also as $V_{\text {ref }}$, goes through an anti-windup process before being compared with the triangular wave to produce the switching signals for $\mathrm{S}_{1}$ to $\mathrm{S}_{6}$. Eventually, $V_{\text {ref }}$ becomes $V_{\text {ref } 1} ; V_{\text {ref } 2}$ and $V_{\text {ref } 3}$ can be derived from $V_{\text {ref } 1}$ by shifting the offset value, which is equivalent to the amplitude of the triangular wave. The mathematical formulation of the PI algorithm and its implementation in the DSP are detailed in [4].

\section{Experiment result}

TMS320F2812 DSP was used to implement the control algorithm. $750 \mathrm{~W}$ PV arrays were used as the inverter's input source. Ten SIEMENS SP75 modules were connected in series to produce $750 \mathrm{~W}$ of peak power. For this experiment prototype, the value of $L_{b}$ is $3 \mathrm{mH}$ and $L_{f}$ is $5 \mathrm{mH}$. Capacitance value of $4400 \mathrm{uF}$ is used for $\mathrm{C}_{1}, \mathrm{C}_{2}$ and $\mathrm{C}_{3}$ respectively. Fig. 3a shows the experiment results for $V_{i n v}$ and $I_{\text {grid }}$. $V_{i n v}$ consists of seven output-voltage levels, and $I_{\text {grid }}$ had been filtered to resemble a pure sinewave. At this instant, the modulation index $M a$ was above 0.66 . The dc-bus voltage was set to $400 \mathrm{~V}$ to inject current into the grid. The waveforms for when $M a$ was reduced, shown in Figures $3 \mathrm{c}$ and $3 \mathrm{e}$.

FLUKE 434 Power Quality Analyzer measured the THD and the power factor. The THD measurement of Fig. $3 \mathrm{~b}$ corresponds to the waveform of Fig. 3a, while THD measurements of Figures $3 \mathrm{~d}$ and $3 \mathrm{f}$ correspond to the waveforms of Figures 3c and 3e, respectively. Comparing all three THD measurements, the seven-level inverter produced the lowest THD compared with the five-level and the three-level ones. This proves that as the level increases, the THD reduces, which is an essential criterion for grid-connected 


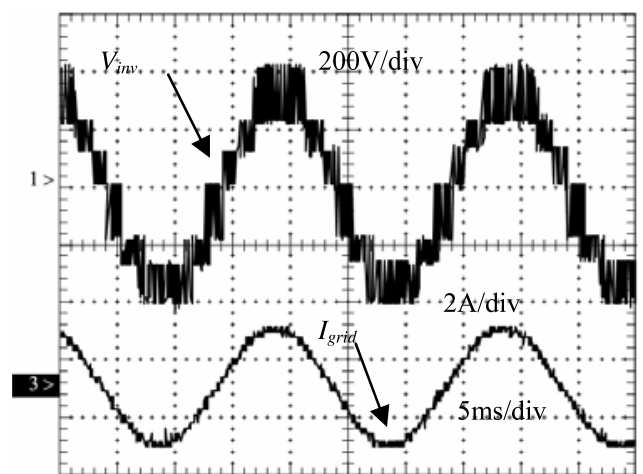

(a)

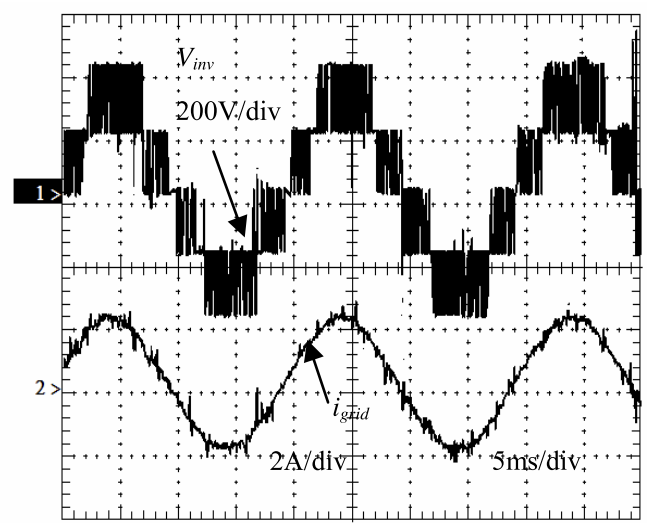

(c)

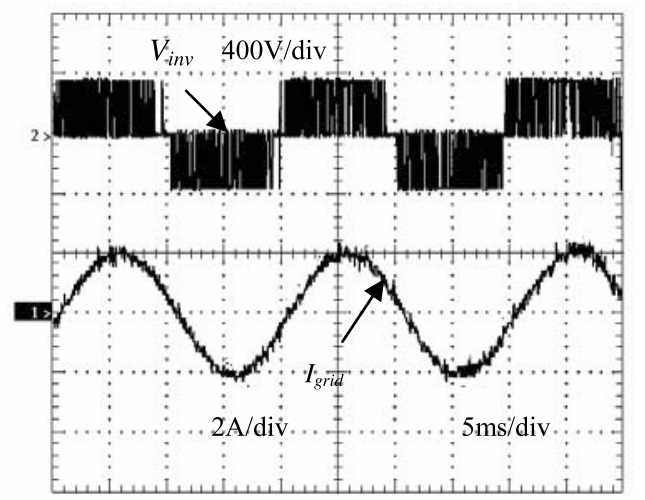

(e)

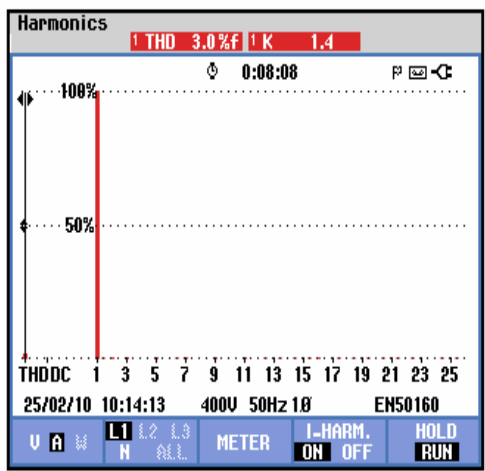

(b)

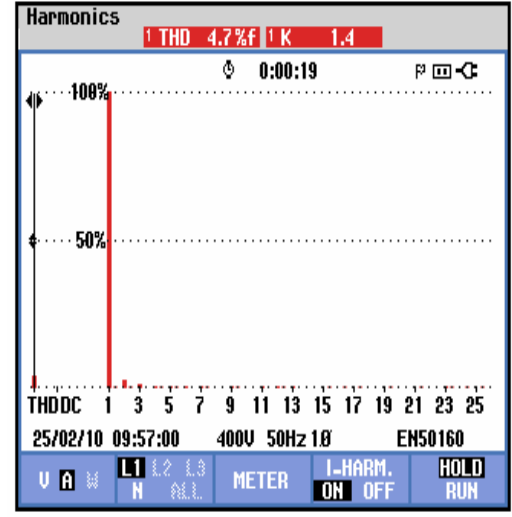

(d)

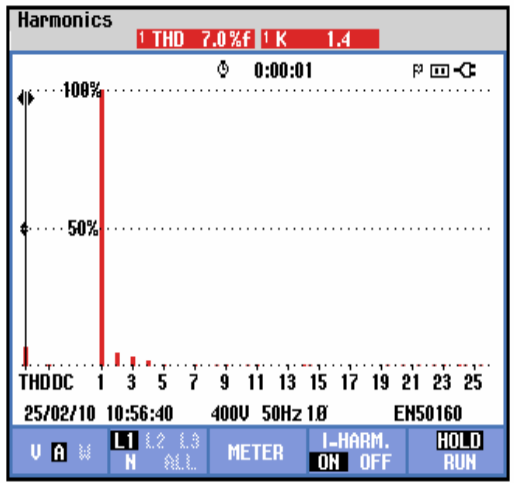

(f)

Fig. 3. (a) Experiment results of $V_{i n v}$ and $I_{\text {grid }}$ for seven levels, (b) current THD for seven levels, (c) $V_{i n v}$ and $I_{\text {grid }}$ for five levels, (d) current THD for five levels, (e) $V_{i n v}$ and $I_{\text {grid }}$ for three levels, (f) current THD for three levels.

PV systems.

\section{Conclusion}

This paper presented a single-phase seven-level inverter for PV application with a novel PWM switching scheme. PWM switching signals were generated by comparing three reference signals with a triangular carrier signal. The circuit topology, control algorithm, and operational principle of the proposed 
inverter were analyzed. By controlling the modulation index, the desired number of levels of the inverter's output voltage can be achieved. Less THD in the seven-level inverter compared with that in the five-level and the threelevel inverters is an attractive solution for grid-connected PV inverters. 